CARPATHIAN JOURNAL OF FOOD SCIENCE AND TECHNOLOGY

journal homepage: http://chimie-biologie.ubm.ro/carpathian_journal/index.html

\title{
GAMMA RADIATION EFFECTS ON PHYSICOCHEMICAL, MICROBIOLOGICAL AND ANTIOXIDANT PROPERTIES OF BLACK RICE (Oryza Sativa L.) FLOUR DURING STORAGE
}

\author{
Vivian Cristina Ito ${ }^{1}$, Acácio Antônio Ferreira Zielinski², Ivo Mottin Demiate', Marta Spoto³, \\ Alessandro Nogueira1, Luiz Gustavo Lacerda ${ }^{4 *}$ \\ ${ }^{1}$ Graduate Program in Food Science and Technology - State University of Ponta Grossa (UEPG), Av. Carlos \\ Cavalcanti 4748 Uvaranas Campus, CEP 84.030-900 - Ponta Grossa-PR - Brazil. \\ ${ }^{2}$ Department of Chemical Engineering and Food Engineering - Federal University of Santa Catarina (UFSC), \\ Florianópolis, SC, 88010-970, Brazil \\ ${ }^{3}$ Centre for Nuclear Energy in Agriculture, University of São Paulo (USP). Av. Centenário, 303, Luiz de \\ Queiroz Campus, 13900-470, Piracicaba, Brazil. \\ ${ }^{4}$ Food Science and Technology Graduate Program - State University of Ponta Grossa (UEPG), Av. Carlos \\ Cavalcanti 4748 Uvaranas Campus, CEP 84.030-900 - Ponta Grossa, Brazil. \\ *lglacerda@uepg.br
}

https://doi.org/10.34302/crpjfst/2019.11.3.14

Article history:

Received:

28 March 2019

Accepted:

29 August 2019

Keywords:

Bioactive compounds;

Irradiation;

Chemometric;

Pigmented rice.

\section{ABSTRACT}

Black rice has been categorised as a functional food because it contains high amounts of bioactive compounds. The effects of gamma radiation (at $0,1,2$ and $3 \mathrm{kGy}$ doses) on the free and bound total phenolics, antioxidant activity, and physicochemical and microbiological properties of black rice flour samples during storage were evaluated. The chemometric approach made it possible to observe the effects of irradiation and storage time on the samples. Regarding bioactive compounds, with the exception of the bound phenolic fractions the $3 \mathrm{kGy}$ dose showed the highest values at time 0. At 120 days there was a decrease in these levels for all the samples, although the irradiated samples were most stable at the end of storage. Regarding the attribute of colour, the irradiation slightly modified all the parameters; in terms of microbiological analysis there was no growth of microorganisms at the end of storage.

\section{Introduction}

Rice (Oryza sativa L.) is one the most important staple foods worldwide; it is considered to be an important source of energy for populations from both developed and developing countries. In the last few years global rice production has been higher than consumption, with an annual production of almost 500 million metric tonnes (milled rice basis) and a harvested area of above 160 million hectares (USDA, 2018).

Even though white rice (non-pigmented) is the most cultivated variety, coloured (pigmented) rice has received increasing attention from researchers due to its antioxidant properties and bioactive compounds in the outer layer of the caryopsis (Finocchiaro et al., 2010; Ryu and Koh, 2017). Rice contains higher levels of phenolic acids (ferulic, caffeic and coumaric acid), than other cereal grains (Ti et al., 2014). Pigmented rice is a source of proanthocyanidins, anthocyanins and flavonoids, as well as tocopherols and vitamins (Hao et al., 2015; Rodríguez-Pérez et al., 2015).

In particular, black rice contains anthocyanins and phenolic acids, which is categorized as free phenolic acids or bound phenolic acids (Ito and Lacerda, 2019). Free 
phenolic acids are extractable mainly by using an $80 \%$ methanol solution. As the bound phenolic acids are present in insoluble form, a strong alkali is added to the residue obtained after the extraction of free phenolics (Alves et al., 2016). These bioactive compounds, which are present in different amounts in rice varieties, are associated with reducing the risks of developing several chronic diseases such as cancer, diabetes, cardiovascular disease (Hao et al., 2015).

It has known that irradiation is a powerful processing technology to inactivate microorganisms and insects to ensure hygienic quality, as well as extending the shelf life of foods. Gamma radiation is considered to be a physical and environmentally friendly technology that is widely acknowledged for its various applications in the food industry (Kumar et al, 2017).

Understanding the effects of radiation by using chemometrics could provide significant information concerning the bioactive compounds that are present in pigmented rice. This is fundamental to develop new food products and to improve human health. Therefore, the purpose of this research was to investigate the effects of gamma radiation on the free and bound total phenolics, antioxidant activity and physicochemical and microbiological properties of black rice flour during storage by using chemometrics.

\section{Materials and methods}

\subsection{Sample preparation and radiation treatment}

All reagents were of the highest grade commercially available. The biodynamic black rice used in the experiments was cultivated according to Demeter biodynamic standards (Demeter International, 2012) and purchased in a local supermarket in the city of Curitiba, Paraná, Brazil. The black rice flour was obtained according to the methodology used by Ito et al. (2018).

All samples were irradiated at doses of 0,1 , 2 and $3 \mathrm{kGy}$ at a $0.221 \mathrm{kGy} \mathrm{h}^{-1}$ dose rate in a ${ }^{60} \mathrm{Co}$ gamma irradiator (Gammacell Excell 220 -
MDS Nordion, Ottawa, Canada). The irradiation treatments were performed in the Centre for Nuclear Energy in Agriculture at the University of São Paulo, Brazil (CENA/USP).

\subsection{Physicochemical analysis}

The colour attributes lightness $\left(L^{*}\right)$, redness $\left(a^{*}\right)$, and yellowness $\left(b^{*}\right)$ of the black rice flour samples were determined using a HunterLab MiniScan EZ colourimeter (Reston, VA, USA.), as described by Ito et al., 2016.

The moisture was determined gravimetrically in an air oven at $105^{\circ} \mathrm{C}$ (AOAC 935.29). The water activity $\left(\mathrm{A}_{\mathrm{w}}\right)$ was measured with a digital $A_{w}$ meter (Aqualab ${ }^{\circledR}$, USA).

\subsection{Extraction and phenolic composition 2.3.1. Extraction of free and bound phenolics}

The free phenolics were extracted using the method reported by Sumczynski et al. (2016) with minor modifications. Briefly, the sample $(0.5 \mathrm{~g})$ of black rice flour was treated twice with $8 \mathrm{~mL}$ of $80 \%$ aqueous methanol using an ultrasound device $(47 \mathrm{kHz}, 130 \mathrm{~W}$, Ultrasonic Cleaners, Vernon Hills, USA) at $35^{\circ} \mathrm{C}$ for $1 \mathrm{~h}$.

The supernatants were combined after centrifugation at $5000 \mathrm{~g}$ (HIMAC CR-GII, Hitachi, Ibaraki, Japan) for $30 \mathrm{~min}$ at room temperature and their $\mathrm{pH}$ was adjusted to 4.5-5.5.

To extract the bound phenolics the residues of black rice flour obtained above were rewashed using $20 \mathrm{~mL}$ of water. After removing the water the samples were blended twice with $20 \mathrm{~mL}$ of $4 \mathrm{M} \mathrm{NaOH}$ for $2 \mathrm{~h}$ in an ultrasonic device. The mixture was then adjusted. After centrifugation, the supernatant was used as the bound phenolic extract.

\subsubsection{Phenolic composition}

The free and bound phenolic fractions were determined by colorimetric analysis using FolinCiocalteu reagent, as described by Singleton, and Rossi (1965), with modifications. The absorbance was recorded at a wavelength of $720 \mathrm{~nm}$ after one hour of reaction and the measurements were performed using a 
microplate reader (Epoch microplate spectrophotometer, Synergy-BioTek, Winooski, VT, USA). The total phenolic content was calculated as the sum of the free and bound phenols. The results were expressed as $\mathrm{mg}$ of gallic acid equivalents (GAE) per gram of black rice flour ( $\left.\mathrm{mg} \mathrm{GAE} \mathrm{g}^{-1}\right)$.

The total anthocyanins content (TAC) was determined according to the $\mathrm{pH}$ differential spectrophotometric method adapted for microplate (Giusti \& Wrolstad, 2001). Firstly, two solutions were prepared: one buffer at $\mathrm{pH}$ $1.0\left(0.025 \mathrm{~mol} \mathrm{~L}^{-1} \mathrm{KCl}\right.$ water buffer, acidified with $\mathrm{HCl})$ and another buffer at $\mathrm{pH} 4.5(0.4 \mathrm{~mol}$ $\mathrm{L}^{-1}$ sodium acetate water buffer, acidified with $\mathrm{HCl})$. Subsequently, using the method reported by Shao et al. (2014), aliquots of the extract were transferred to a 96-well microplate and $290 \mu \mathrm{L}$ of corresponding buffer ( $\mathrm{pH} 1.0$ and 4.5) and allowed to equilibrate for $30 \mathrm{~min}$. The absorbance was measured at 520 and $700 \mathrm{~nm}$. The TAC was expressed as mg cyanidin-3glucoside equivalent $(\mathrm{C} 3 \mathrm{G})$ per $\mathrm{g}$ of black rice flour.

The anthocyanin extracts were also analysed using HPLC, as previously described by Pedro et al. (2016), with minor changes. The analysis was performed in an Alliance 2695 separation module (Waters, Milford, MA, USA) coupled with photodiode detector (model PDA 2998, Waters, Milford, MA, USA), a quaternary pump and an auto sampler. Firstly, the extracts were filtered then $10 \mu \mathrm{L}$ of sample was injected into the HPLC system. The separation was then performed using a XTerra ${ }^{\circledR}$ MS C18 column with dimensions of $4.6 \times 250 \mathrm{~mm}, \quad 5 \mu \mathrm{m}$ (Waters, Milford, MA, USA) kept at $20{ }^{\circ} \mathrm{C}$ with a flow of $1.0 \mathrm{~mL} \mathrm{~min}{ }^{-1}$. The black rice flour anthocyanins were identified and quantified at $515 \mathrm{~nm}$ using a DAD detector by comparing the retention time with the standard of cyanidin-3glucoside in the concentration range from 0.01 to $\quad 0.25 \mathrm{mg} \mathrm{L}^{-1} \quad(y=25482 x-20152$; $R^{2}=0.999$ ).

The total flavonoids (TF) were quantified by UV-Vis spectrophotometry (Shimadzu UV1800) at $374 \mathrm{~nm}$ as described by Pedro et al,
(2016). The total flavonoid content was expressed as mg quercetin equivalents $(\mathrm{QE})$ per $\mathrm{g}$ of black rice flour.

\subsection{In vitro antioxidant activity}

The total antioxidant potential of the black rice flour extracts was determined by assessing the ABTS scavenging activity of the extracts using the method described by Re et al. (1999), with modifications. The absorbance was recorded at a wavelength of $734 \mathrm{~nm}$ after the solution had been allowed to stand in the dark for $30 \mathrm{~min}$. The results were compared with a standard curve (trolox 100-1000 $\mu \mathrm{mol} \mathrm{L}^{-1}$ ) and expressed in $\mu \mathrm{moL}$ trolox equivalent per $\mathrm{g}$ of black rice flour $\left(\mu \mathrm{mol} \mathrm{TE} \mathrm{g}^{-1}\right)$.

The DPPH radical scavenging activity of the extracts was determined according to the method of Brand Williams et al. (1995), with minor modifications. The absorbance was recorded at a wavelength of $517 \mathrm{~nm}$ after the solution had been allowed to stand in the dark for 30 min. A standard curve $\left(\mathrm{DPPH}=0.001 \times\right.$ absorbance; $\quad R^{2}=0.995$; $p<0.001)$ was plotted using different concentrations of trolox $\left(0.1-300 \mu \mathrm{mol} \mathrm{L}^{-1}\right)$. The results were expressed in $\mu$ mol trolox

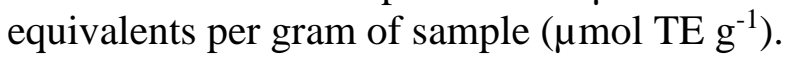

\subsection{Microbiological analysis}

In order to evaluate the microbiological quality of the black rice flour, the following analyses were performed: Bacillus cereus, thermotolerant coliforms and Salmonella sp, according to the National Health Surveillance Agency, Collegiate Board Resolution No. 12 (ANVISA, 2001). In this study, the samples were included in the food group "flour, pasta and bakery products (industrialised and packaged) and similar" with a maximum tolerance for an indicative sample being $3 \times 10^{3} \mathrm{NMP} \mathrm{g}^{-1}$ or $\mathrm{CFU}$ $\mathrm{g}^{-1}$ of Bacillus cereus; $10^{2} \mathrm{NMP} \mathrm{g}^{-1}$ or CFU g ${ }^{-1}$ of thermotolerant coliform; and the absence of Salmonella sp in 25 grams. The analyses were performed in triplicate during the first and last stages of the research.

\subsection{Statistical analysis}


The experimental data were presented as the mean \pm standard deviation. The analyses were performed using STATISTICA v.13.3 software (TIBCO Software Inc., Palo Alto, CA, USA). One-way analysis of variance (ANOVA) was used to study the effects of gamma radiation on bioactive compounds, antioxidant activity and colour parameters. Duncan's tests were conducted to determine differences between the means at $95 \%$ confidence level ( $\mathrm{p}<0.05$ ). Pearson's correlation analysis (r) was applied between the different response variables to assess the strength of the correlation between the responses.

Principal component analysis (PCA) was used to analyse the interrelationships between the parameters. The hierarchical cluster analysis (HCA) was based on Euclidean distance and Ward's method. In order to compare the results between the groups proposed by HCA, homogeneity of variance (Levene's test) and analysis of variance (one-way ANOVA or Kruskal-Wallis ANOVA) were applied (Ito et al., 2016).

\section{Results and discussions}

3.1. Effects of gamma radiation on bioactive compounds and antioxidant activity during storage

The results obtained for phenolic compounds (PC) and antioxidant activity by the ABTS and DPPH assays regarding the free, bound and total phenolic fractions of the black rice flour are summarised in Table 1. Analysing the values for PC and antioxidant activity (ABTS and DPPH) of the free phenolic fraction of the black rice flour, it was observed that the sample with a $3 \mathrm{kGy}$ dose showed the highest values compared with the samples treated with doses of 0,1 and $2 \mathrm{kGy}$. At 120 days there was a decrease in the levels for all the samples $(\mathrm{p}<0.05)$.

Table 1..Effects of gamma radiation on the levels of phenolic compounds (PC) and antioxidant activity of free, bound and total phenolic fractions of black rice flour at the beginning ( $\mathrm{T}_{0}$-zero days) and end of storage $\left(\mathrm{T}_{\mathrm{f}-1} 120\right.$ days).

\begin{tabular}{|c|c|c|c|}
\hline Analysis & $\begin{array}{c}\text { Doses } \\
(\mathbf{k G y})\end{array}$ & $\mathbf{T}_{\mathbf{0}}(\mathbf{0}$ days) & $\mathbf{T}_{\mathbf{f}}(\mathbf{1 2 0}$ days $)$ \\
\hline Free PC & 0 & $5.28^{\mathrm{Da}} \pm 0.03$ & $3.25^{\mathrm{Cb}} \pm 0.04$ \\
(mgGA g) & 1 & $5.79^{\mathrm{Ba}} \pm 0.03$ & $3.58^{\mathrm{ABb}} \pm 0.03$ \\
& 2 & $5.67^{\mathrm{Ca}} \pm 0.01$ & $3.54^{\mathrm{Bb}} \pm 0.03$ \\
\hline Bound PC & 3 & $5.89^{\mathrm{Aa}} \pm 0.03$ & $3.64^{\mathrm{Ab}} \pm 0.03$ \\
(mgGA g) & 1 & $1.84^{\mathrm{Aa}} \pm 0.02$ & $0.95^{\mathrm{Db}} \pm 0.03$ \\
& 2 & $1.67^{\mathrm{Ba}} \pm 0.02$ & $0.99^{\mathrm{BCb}} \pm 0.04$ \\
& 3 & $1.61^{\mathrm{Ca}} \pm 0.02$ & $1.09^{\mathrm{Ab}} \pm 0.02$ \\
Total PC & 0 & $7.59^{\mathrm{Ca}} \pm 0.01$ & $1.01^{\mathrm{Bb}} \pm 0.02$ \\
(mgGA g) & 1 & $7.12^{\mathrm{Ca}} \pm 0.02$ & $4.16^{\mathrm{Bb}} \pm 0.06$ \\
& 2 & $7.28^{\mathrm{Ba}} \pm 0.03$ & $4.57^{\mathrm{Ab}} \pm 0.06$ \\
& 3 & $7.47^{\mathrm{Aa}} \pm 0.03$ & $4.63^{\mathrm{Ab}} \pm 0.01$ \\
\hline Free ABTS & 0 & $6.37^{\mathrm{Da}} \pm 0.03$ & $5.15^{\mathrm{Ab}} \pm 0.05$ \\
(mgGA g) & 1 & $7.35^{\mathrm{Ca}} \pm 0.03$ & $6.05^{\mathrm{Bb}} \pm 0.03$ \\
& 2 & $7.59^{\mathrm{Ba}} \pm 0.01$ & $6.16^{\mathrm{Cb}} \pm 0.02$ \\
& 3 & $8.13^{\mathrm{Aa}} \pm 0.02$ & $6.77^{\mathrm{Ab}} \pm 0.03$ \\
\hline Bound ABTS & 0 & $2.52^{\mathrm{Aa}} \pm 0.03$ & $1.60^{\mathrm{Cb}} \pm 0.03$ \\
(mgGA g) & 1 & $2.48^{\mathrm{Ba}} \pm 0.03$ & $1.61^{\mathrm{Bb}} \pm 0.03$ \\
& 2 & $2.36^{\mathrm{Ca}} \pm 0.01$ & $1.63^{\mathrm{Ab}} \pm 0.02$ \\
\hline
\end{tabular}




\begin{tabular}{|c|c|c|c|}
\hline & 3 & $2.35^{\mathrm{Da}} \pm 0.03$ & $1.63^{\mathrm{Ab}} \pm 0.02$ \\
\hline Total ABTS & 0 & $8.89^{\mathrm{Da}} \pm 0.01$ & $6.80^{\mathrm{Db}} \pm 0.01$ \\
(mgGA g) & 1 & $9.83^{\mathrm{Ca}} \pm 0.06$ & $7.66^{\mathrm{Cb}} \pm 0.04$ \\
& 2 & $9.96^{\mathrm{Ba}} \pm 0.02$ & $7.79^{\mathrm{Bb}} \pm 0.01$ \\
& 3 & $10.48^{\mathrm{Aa}} \pm 0.01$ & $8.40^{\mathrm{Ab}} \pm 0.05$ \\
\hline Free DPPH & 0 & $6.19^{\mathrm{Da}} \pm 0.03$ & $4.95^{\mathrm{Db}} \pm 0.03$ \\
(mgGA g) & 1 & $6.37^{\mathrm{Ca}} \pm 0.03$ & $5.01^{\mathrm{Bb}} \pm 0.03$ \\
& 2 & $6.60^{\mathrm{Ba}} \pm 0.02$ & $5.13^{\mathrm{Bb}} \pm 0.02$ \\
& 3 & $6.68^{\mathrm{Aa}} \pm 0.02$ & $5.14^{\mathrm{Ab}} \pm 0.03$ \\
\hline Bound DPPH & 0 & $2.14^{\mathrm{Aa}} \pm 0.03$ & $1.31^{\mathrm{Cb}} \pm 0.02$ \\
(mgGA g) & 1 & $2.09^{\mathrm{Ba}} \pm 0.03$ & $1.31^{\mathrm{Cb}} \pm 0.01$ \\
& 2 & $2.05^{\mathrm{Ca}} \pm 0.01$ & $1.33^{\mathrm{Bb}} \pm 0.03$ \\
Total DPPH & 3 & $2.03^{\mathrm{Da}} \pm 0.02$ & $1.34^{\mathrm{Ab}} \pm 0.02$ \\
(mgGA g) & 1 & $8.33^{\mathrm{Da}} \pm 0.06$ & $6.26^{\mathrm{Db}} \pm 0.01$ \\
& 2 & $8.47^{\mathrm{Ca}} \pm 0.01$ & $6.32^{\mathrm{Cb}} \pm 0.03$ \\
& 3 & $8.65^{\mathrm{Ba}} \pm 0.03$ & $6.46^{\mathrm{Bb}} \pm 0.05$ \\
& $8.72^{\mathrm{Aa}} \pm 0.04$ & $6.48^{\mathrm{Ab}} \pm 0.01$ \\
\hline
\end{tabular}

Note - Results are expressed as mean \pm standard deviation; Different capital letters in the same column indicate significant difference between the doses; Different small letters in the same line indicate significant differences during the time of storage. The significant differences at a level of 5\% were performed by Duncan's test.

This increase in PC and antioxidant activity of the free phenolic fraction of gamma irradiated samples can be ascribed to the development of new double bonds due to of radiation degradation, which reduced the reactivity of the free radicals (Kumar et al., 2017). Another explanation is that, gamma irradiation may modify/activate some enzymes in rice and change the post-harvest physiology during storage (at room temperature), resulting in an improved synthesis of phenolic acids (Zhu et al., 2010).

The total phenolic content showed behaviour that was similar to that of the free fractions, where the irradiated samples showed the highest values compared with control sample $(\mathrm{p}<0.05)$; both at the beginning $\left(\mathrm{T}_{0}\right)$ and at the end $\left(\mathrm{T}_{\mathrm{f}}\right)$. The free phenolic fractions accounted for about $78 \%$ of the total phenolic contents and $77 \%$ of the total antioxidant activity (ABTS and DPPH assays) in the irradiated samples. The main phenolic acids found in pigmented rice are protocatechuic, synaptic, vanillic, p-coumaric and ferulic acid (Zhang et al., 2015).

The values for PC and antioxidant activity of the bound phenolic fraction showed behaviour that was distinct from the free phenolic fraction of the black rice flour. The levels of the control sample were highest at time 0 ; however, the irradiated samples were most stable at the end of storage $(p<0.05)$. The concentration of these phenolic fractions may be dependent on the radiation dosage, the time of storage, technological processes and also the specific nature of the product. Zhang et al., (2015) also found the TPC in soluble fractions were higher than insoluble bound fractions in the black rice; it could be due to some genes that control the linkage between phenolics and lignins which assorted resulting in different offsprings of rice.

Total flavonoids comprise a hydrophilic group of phenolic compounds, to which anthocyanins (highly coloured substances that are recognised for their antioxidant activity and are responsible for the red-purple colour of most vegetables) belong. Cyanidin-3-glucoside ( $88 \%$ of total anthocyanins) is a major anthocyanin in black rice (Abdel-Aal et al., 2006).

Evaluating the total anthocyanin content (TAC), cyanidin-3-glucoside $(\mathrm{C} 3 \mathrm{G})$ and total flavonoids (TF) at 120 days, the results were significantly different $(\mathrm{p}<0.05)$ for all samples. The TAC values ranged from $1.84-1.52$ 
mgC3G.g- ${ }^{1}$; cyanidin-3-glucoside ranged from $1.43-1.26 \mathrm{mg} \cdot \mathrm{g}^{-1}$ and TF ranged from $0.65-$ $0.49 \mathrm{mgCE} . \mathrm{g}^{-1}$. It is noteworthy that the sample with a $3 \mathrm{kGy}$ dose at time 0 showed the highest values, and the control sample (0 kGy) at 120 days showed the lowest values. Sultan et al. (2018) also found a significant increase in TAC in pigmented brown rice flour using an irradiation dose of 2.5 and $5 \mathrm{kGy}$, as well as Zhu et al. (2010), who evaluated brown rice at an irradiation dose of $6 \mathrm{kGy}$.

\subsection{Effects of gamma radiation on colour attributes during storage}

With regard to the effects of gamma radiation on the colour attributes of the black rice flour during storage, the irradiation slightly modified all the parameters $(\mathrm{p}<0.05)$, as shown in Figure 1.
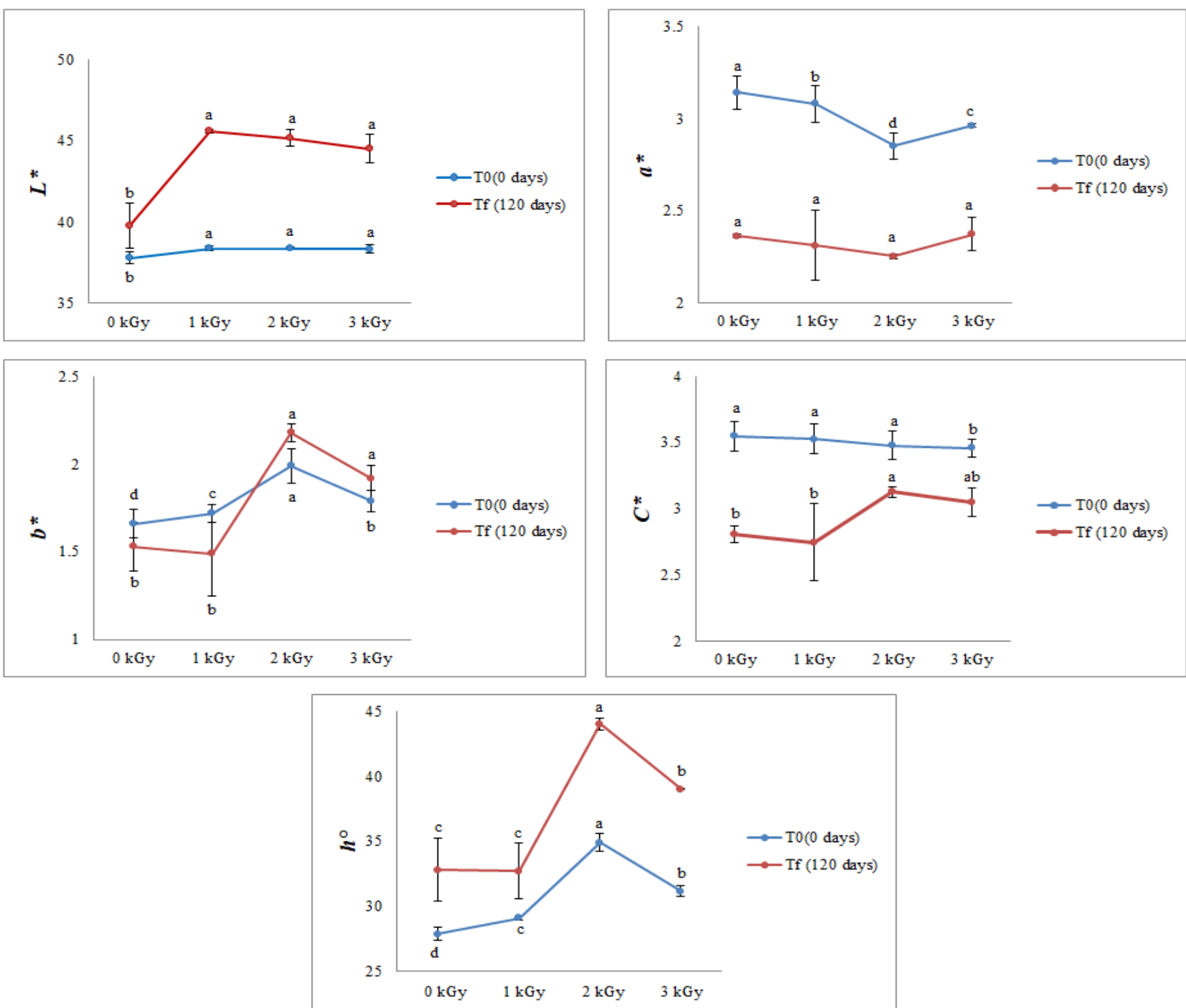

Figure 1. Effects of gamma radiation on the colour attributes $\left(L^{*}, a^{*}, b^{*}, C^{*}\right.$ and $\left.h^{\circ}\right)$ of black rice flour at the beginning ( $\mathrm{T}_{0}$ - zero days) and end $\left(\mathrm{T}_{\mathrm{f}}\right)$ of storage.

In the irradiated samples, the values for Lightness $\left(L^{*}\right)$ and hue angle $\left(h^{\circ}\right)$ were higher than the control sample. Moreover, these

parameters increased for all the samples during storage, indicating a loss of colour intensity. $L^{*}$ is negatively correlated to colour intensity 
(Lago-Vanzela et al., 2014) and this behaviour may be associated with a decrease in phenolic content (Figueiredo-González et al., 2013). The $a^{*}$ (red-green) values were lower in the irradiated samples and during storage this parameter decreased for all the samples.

The irradiated sample with a $2 \mathrm{kGy}$ dose showed higher values for the $b^{*}$ (yellow-blue) parameter and during storage the best stability for the chroma $\left(C^{*}\right)$ parameter. The effects of gamma radiation on the colour parameters have been reported by other authors. For example, slight changes were found in hazelnuts and almond kernels treated with low doses (Mexis and Kontominas, 2009; Mexis et al., 2009). Therefore, these effects differed due to the individual characteristics of each product.

\subsection{Multivariate analysis}

The principal component analysis shown in Figure 2 relates to a two-dimensional graphical representation of the black rice flour samples.
Principal Components 1 (eigenvalue 13.62) and 2 (eigenvalue 2.28) explained $93.5 \%$ of the variance of the data. The formation of two clusters based on the time of storage can be observed.

The left area of Principal Component 1 contained the samples with higher levels of free, bound and total PC, free bound and total DPPH, bound and total ABTS, TAC, TF and $C^{*}$. The right area of Principal Component 1 contained the samples with higher values for the $a^{*}$ parameter. The upper area of Principal Component 2 contained a concentration of samples with higher levels of cianidin-3glucoside, free ABTS, $L^{*}, b^{*}$ and $h^{\circ}$.

The samples analysed at day 0 , were located in the second and third quadrants (left side) and the samples analysed at 120 days were located in the first and fourth quadrants. PCA was an appropriate approach to verify the differences between the gamma radiation doses and storage time in the samples of black rice flour.

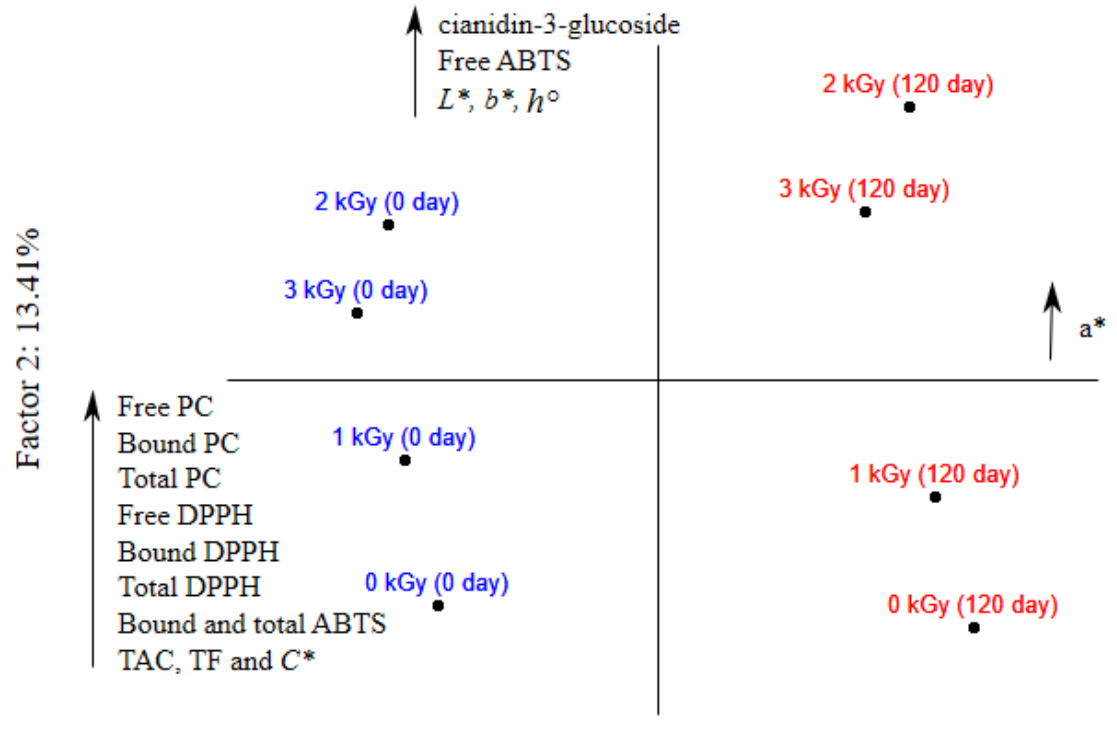

Factor 1: $80.09 \%$

Figure 2. A scatter plot (Principal Component $1 \times$ Principal Component 2 ) in relation to free, bound and total phenolic compounds, antioxidant activity and colour attributes in irradiated black rice flour during 120 days of storage.

The dendrogram in Figure 3 shows the association between the studied variables. The TAC showed a strong association and positive correlation with the free and total PC $(\mathrm{r}=0.96$; $\mathrm{p}<0.001)$ and free and total antioxidant activity by DPPH $(r=0.97 ; p<0.001)$. The TAC was 
also positively correlated with cianidin-3glucoside $(\mathrm{r}=0.76 ; \mathrm{p}<0.05), \mathrm{TF}(\mathrm{r}=0.96 ; \mathrm{p}<$ $0.001)$, free and total ABTS $(r=0.94 ; \mathrm{p}<0.05)$ and the $C^{*}$ parameter $(\mathrm{r}=0.93 ; \mathrm{p}<0.05)$. The bound PC, bound ABTS and bound DPPH also showed a strong association and positive correlation $(\mathrm{r}=0.99 ; \mathrm{p}<0.001)$, as well as the cianidin-3-glucoside and free ABTS $(r=0.96 ; p$ $<0.05)$. Several studies have also demonstrated that phenolic content has a highly positive correlation with antioxidant activities (Shen et al., 2009; Shao et al., 2013).

The $L^{*}$ and $a^{*}$ colour parameters showed a strong association and positive correlation $(\mathrm{r}=$ $0.83 ; \mathrm{p}<0.05)$; in relation to the $h^{\circ}$ attribute there was an association with $b^{*}(\mathrm{r}=0.74 ; \mathrm{p}<$ $0.05)$.

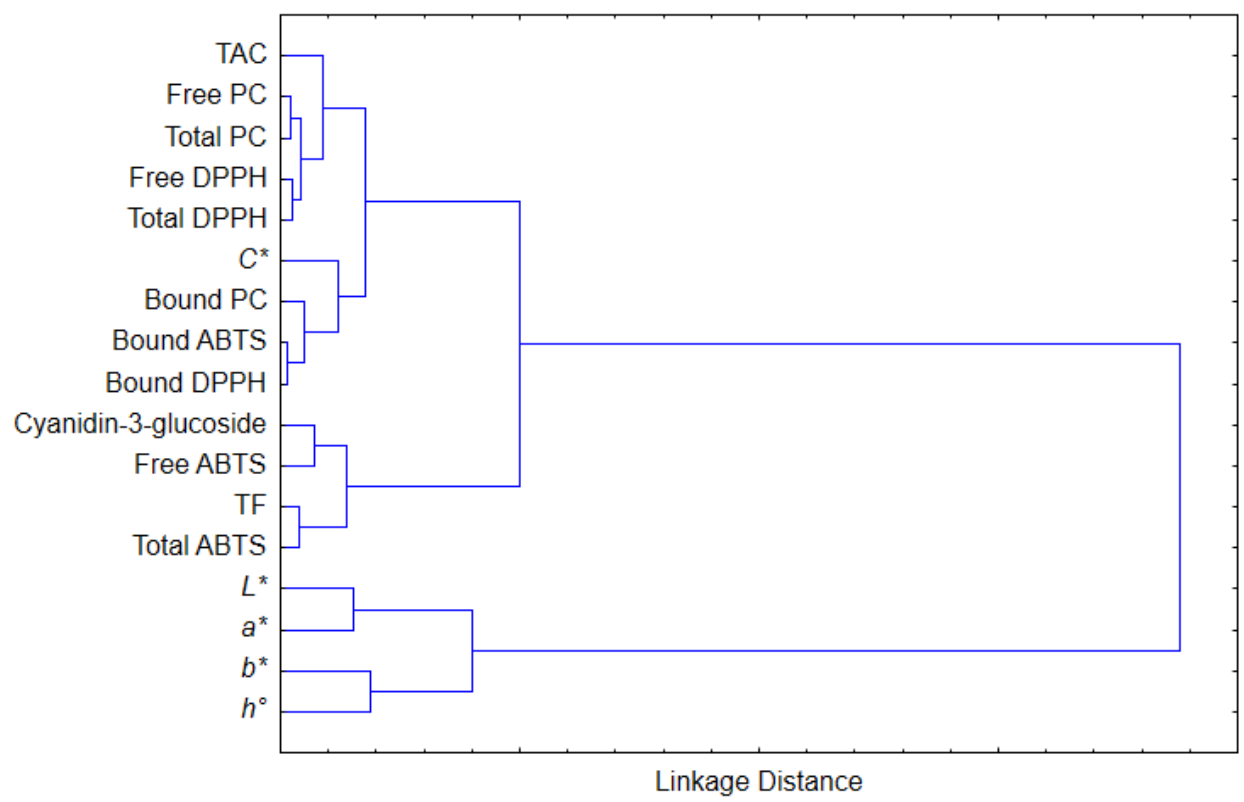

Figure 3. Dendrogram obtained from hierarchical cluster analysis for irradiated black rice flour during 120 days of storage applied to the variables in relation to free, bound and total phenolic compounds, antioxidant activity and colour attributes.

The similarity of the samples was evaluated by using hierarchical cluster analysis, where two clusters were suggested (Figure 4). Cluster 1 was characterised by samples analysed at 0 days and Cluster 2 was characterised by samples that were analysed at 120 days Table 2 shows that the means for each dependent variable were compared, and the ANOVA results for the clusters obtained by hierarchical cluster analysis were calculated.
Cluster 1 (0 days) had higher values for all the parameters, except $(\mathrm{p}>0.05)$ for cianidin-3glucoside, $b^{*}$ and $h^{\circ}$. Cluster 2 (120 days) showed lower values, which could have been due to the period of storage. 


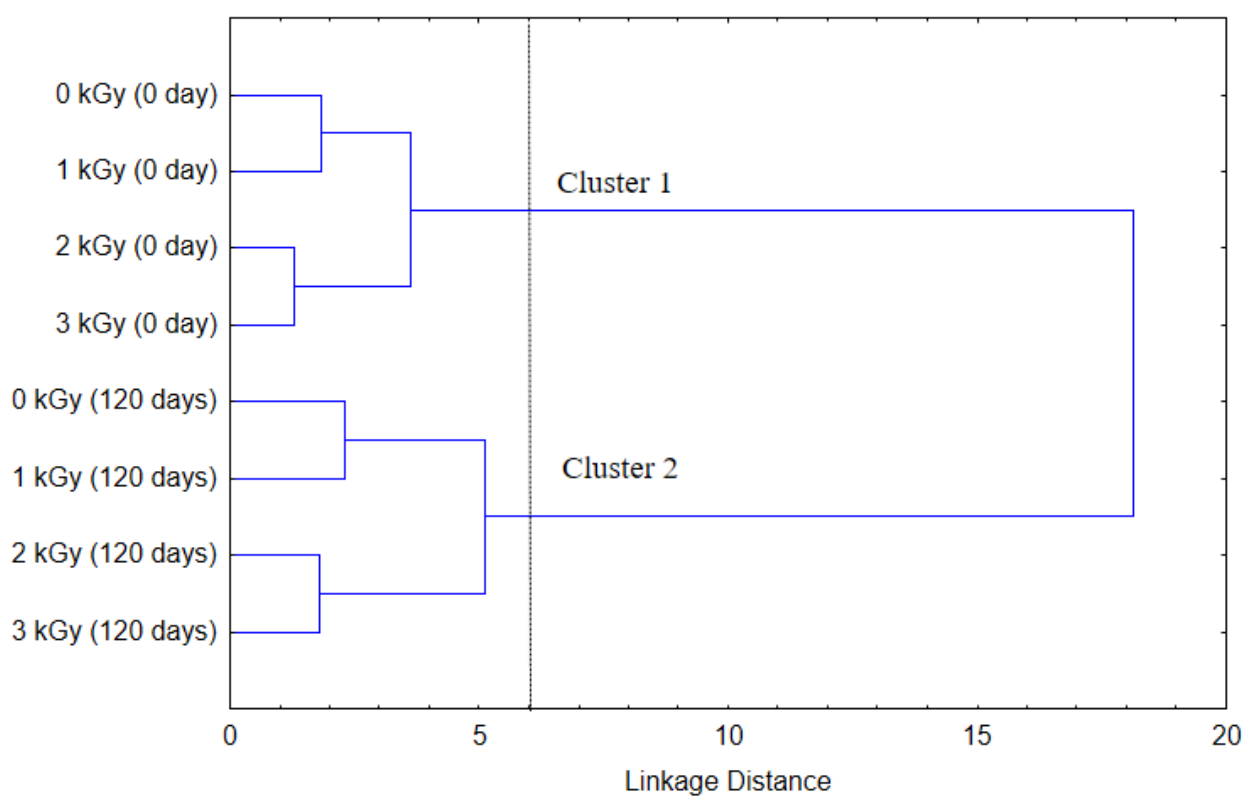

Figure 4. Dendrogram obtained from hierarchical cluster analysis for irradiated black rice flour during 120 days of storage applied to the samples in relation to free, bound and total phenolic compounds, antioxidant activity and colour attributes.

Table 2.Phenolic content - PC (mg GA g); antioxidant activity - ABTS and DPPH ( $\mu$ mol TE g), total anthocyanin content - TAC ( $\left.\mathrm{mg} \mathrm{C} \mathrm{G} \mathrm{g} \mathrm{g}^{-1}\right)$, cianidin-3-glucoside $\left(\mathrm{mg} \mathrm{g}^{-1}\right)$, total flavonoids - TF (mg QE $\mathrm{g}^{-1}$ ) and colour attributes of irradiated black rice flour using hierarchical cluster analysis (HCA).

\begin{tabular}{|c|c|c|c|c|c|}
\hline Variables & $\begin{array}{c}\text { Cluster 1 } \\
\mathbf{n = 4}\end{array}$ & $\begin{array}{c}\text { Cluster 2 } \\
\mathbf{n = 4}\end{array}$ & PSD & p-value* & p-value** \\
\hline Free PC & $5.66^{\mathrm{a}}$ & $3.50^{\mathrm{b}}$ & 1.53 & 0.52 & $<0.05^{*}$ \\
\hline Free ABTS & $7.36^{\mathrm{a}}$ & $6.04^{\mathrm{b}}$ & 0.93 & 0.81 & $<0.05^{*}$ \\
\hline Free DPPH & $6.46^{\mathrm{a}}$ & $5.06^{\mathrm{b}}$ & 0.99 & 0.05 & $<0.05^{*}$ \\
\hline Bound PC & $1.68^{\mathrm{a}}$ & $1.01^{\mathrm{b}}$ & 0.47 & 0.30 & $<0.05^{*}$ \\
\hline Bound ABTS & $2.43^{\mathrm{a}}$ & $1.61^{\mathrm{b}}$ & 0.58 & $<0.001$ & $<0.05^{*}$ \\
\hline Bound DPPH & $2.08^{\mathrm{a}}$ & $1.32^{\mathrm{b}}$ & 0.54 & $<0.05$ & $<0.05^{*}$ \\
\hline TAC & $1.81^{\mathrm{a}}$ & $1.58^{\mathrm{b}}$ & 0.16 & 0.67 & $<0.05^{*}$ \\
\hline Cianidin-3-glucoside & 1.38 & 1.31 & 0.05 & 0.25 & 0.14 \\
\hline TF & $0.63^{\mathrm{a}}$ & $0.53^{\mathrm{b}}$ & 0.07 & 0.93 & $<0.05^{*}$ \\
\hline $\boldsymbol{L}^{*}$ & $43.7^{\mathrm{a}}$ & $38.17^{\mathrm{b}}$ & 3.91 & $<0.05$ & $<0.05^{*}$ \\
\hline $\boldsymbol{a}^{*}$ & $2.32^{\mathrm{a}}$ & $1.38^{\mathrm{b}}$ & 0.66 & 0.98 & $<0.05^{*}$ \\
\hline $\boldsymbol{b}^{*}$ & 1.79 & 1.78 & 0.01 & $<0.05$ & 0.77 \\
\hline $\boldsymbol{C}^{*}$ & $3.5^{\mathrm{a}}$ & $2.93^{\mathrm{b}}$ & 0.40 & $<0.05$ & $<0.05^{*}$ \\
\hline $\boldsymbol{h}^{\circ}$ & 37.15 & 30.77 & 4.51 & 0.16 & 0.08 \\
\hline
\end{tabular}

Note: Results expressed as mean \pm pooled standard deviation. PSD: pooled standard deviation; *Probability values obtained by Levene's test for homogeneity of variances; **Probability values obtained by one-way ANOVA or Kruskal-Wallis test. Different letters in the same line represent statistically different results $(p<0.05)$. 
3.4. Effects of gamma radiation on physicochemical and microbiological properties during storage

There was an increase in all the samples during 120 days of storage regarding moisture and water activity $\left(\mathrm{A}_{\mathrm{w}}\right)$. The moisture content ranged from 10.54 ( $3 \mathrm{kGy}-0$ days) to 11.60 g.100g-1 (0 kGy - 120 days) and $A_{w}$ values ranged from 0.41 ( 2 and $3 \mathrm{kGy}-0$ days) to 0.48 (0 kGy - 120 days). The control sample (0 kGy) had the highest increase, $9.02 \%$ for moisture and $14.94 \%$ for $A_{w}$. This increase can be associated with the hygroscopic of flours and their tendency to respond to changes in ambient relative humidity, as well as the transfer properties of water vapour from the packaging.

Similar results were found by Silva et al. (2010), who evaluated the oxidative stability in irradiated wheat flour and cornmeal, and who observed a significant increase in moisture in the samples from the first 30 days onwards. Marathe et al. (2002) found that moisture levels in irradiated and non-irradiated wheat flour increased at 120 days of storage.

Regarding the microbiological analyses, the results were below those required by legislation (ANVISA, 2001). In the control sample (0 kGy), the colony-forming units per gram $\mathrm{CFU} \mathrm{g}{ }^{-1}$ were $<10^{2}$ for Bacillus cereus; the most probable number per gram NMP $\mathrm{g}^{-1}$ was $<3.0$ for thermotolerant coliforms; and there was an absence of Salmonella sp in 25 grams. There was no growth of microorganisms during the storage period of 120 days. In the irradiated samples $(1,2$ and $3 \mathrm{kGy})$ there were nondetectable values for these bacteria. Feliciano et al., (2017) demonstrated the effectiveness of low-dose gamma irradiation for the microbial decontamination of brown rice for a prolonged period of storage in ambient conditions.

\section{Conclusions}

Our study concluded that the effects of gamma - radioisotope ${ }^{60} \mathrm{Co}$ on black rice flour resulted in an increase in phenolic compounds and antioxidant activity of the free and total phenolic fraction, as well as total anthocyanins content, cyanidin-3-glucoside and total flavonoids. The dose of $3 \mathrm{kGy}$ showed the highest values; at 120 days there was a decrease in these levels for all samples. However, the irradiated samples were most stable at the end of storage. With regard to the colour attributes, the irradiation slightly modified all the parameters. For the microbiological analysis, there was no growth of microorganisms in the samples during the storage period of 120 days.

The results demonstrated that the chemometric approach proved to be effective in facilitating the visualisation of the positive effects of irradiation, which may improve the shelf life of black rice flour. This pigmented rice can be a valuable ingredient in gluten-free, cereal products with higher nutritional value, as well as helping to partially reduce negative impacts on the environment.

\section{References}

Abdel-Aal, E.-S. M., Young, J. C., \& Rabalski, I. (2006). Anthocyanin Composition in Black, Blue, Pink, Purple, and Red Cereal Grains. Journal of Agricultural and Food Chemistry, 54(13), 4696-04.

Alves, G. H., Ferreira, C. D., Vivian, P. G., Monks, J. L. F., Elias, M. C., Vanier, N. L., $\&$ de Oliveira, M. (2016). The revisited levels of free and bound phenolics in rice: Effects of the extraction procedure. Food Chemistry, 208, 116-23.

ANVISA. (2001). Resolução RDC n ${ }^{\circ} 12$ Diário Oficial da União, Brasilia, Available on line:

http://portal.anvisa.gov.br/documents/3388 O/2568070/RDC_12_2001.pdf/15ffddf63767-4527-bfac-740a0400829b (Accessed on May, 13th, 2018).

AOAC. (2005). AOAC - Official methods of analysis. Association of Official Analytical Chemist, Washington, DC, USA, 18th ed.

Brand-Williams, W., Cuvelier, M. E., \& Berset, C. (1995). Use of a free radical method to evaluate antioxidant activity. LebensmittelWissenschaft und-Technologie, 28, 25 - 30. 
Demeter International, \& International, e. D. (2012). Production standards. For the use of demeter, biodynamic and related trademarks. Available on line: http://www.demeter.net/certification/standa rds (Accessed on May, 12th, 2018).

Feliciano, C. P., de Guzman, Z. M., Tolentino, L. M. M., Asaad, C. O., Cobar, M. L. C., Abrera, G. B., Baldos, D. T., Diano, G. T. (2017). Microbiological quality of brown rice, ready-to-eat pre-cut fresh fruits, and mixed vegetables irradiated for immunocompromised patients. Radiation Physics and Chemistry, 130, 397-9.

Figueiredo-González, M., Cancho-Grande, B., \& Simal-Gándara, J. (2013). Garnacha Tintorera-based sweet wines: Chromatic properties and global phenolic composition by means of UV-Vis spectrophotometry. Food Chemistry, 140(1), 217-4.

Finocchiaro, F., Ferrari, B., \& Gianinetti, A. (2010). A study of biodiversity of flavonoid content in the rice caryopsis evidencing simultaneous accumulation of anthocyanins and proanthocyanidins in a black-grained genotype. Journal of Cereal Science, 51(1), 28-4.

Giusti, M. M., \& Wrolstad, R. E. (2001). Characterization and Measurement of Anthocyanins by UV-Visible Spectroscopy Current Protocols in Food Analytical Chemistry: John Wiley \& Sons, Inc.

Hao, J., Zhu, H., Zhang, Z., Yang, S., \& Li, H. (2015). Identification of anthocyanins in black rice (Oryza sativa L.) by UPLC/QTOF-MS and their in vitro and in vivo antioxidant activities. Journal of Cereal Science, 64, 92-9.

Ito, V. C., Alberti, A., Avila, S., Spoto, M., Nogueira, A., \& Wosiacki, G. (2016). Effects of gamma radiation on the phenolic compounds and in vitro antioxidant activity of apple pomace flour during storage using multivariate statistical techniques. Innovative Food Science \& Emerging Technologies, 33, 251-9.
Ito, V. C., Bet, C. D., Wojeicchowski, J. P., Demiate, I. M., Spoto, M. H. F., Schnitzler, E., \& Lacerda, L. G. (2018). Effects of gamma radiation on the thermoanalytical, structural and pasting properties of black rice (Oryza sativa L.) flour. Journal of Thermal Analysis and Calorimetry, 133(1), 529-7.

Ito, V. C., Lacerda, L. G. (2019). Black rice (Oryza sativa L.): a review of its historical aspects, chemical composition, nutritional and functional properties, and applications and processing technologies. Food Chemistry, 301, 125304.

Kumar, P., Prakash, K. S., Jan, K., Swer, T. L., Jan, S., Verma, R., Deepika, Km., Dar, M. K,. Verma, K., Bashir, K. (2017). Effects of gamma irradiation on starch granule structure and physicochemical properties of brown rice starch. Journal of Cereal Science, 77, 194-0.

Lago-Vanzela, E. S., Procópio, D. P., Fontes, E. A. F., Ramos, A. M., Stringheta, P. C., DaSilva, R., Castillo-Muñoz, N., HermosínGutiérrez, I. (2014). Aging of red wines made from hybrid grape cv. BRS Violeta: Effects of accelerated aging conditions on phenolic composition, color and antioxidant activity. Food Research International, 56(Supplement C), 182-9.

Marathe, S. A., Machaiah, J. P., Rao, B. Y. K., Pednekar, M. D., \& Rao, V. A. (2002). Extension of shelf-life of whole-wheat flour by gamma radiation. International Journal of Food Science \& Technology, 37(2), 1638.

Mexis, S. F., Badeka, A. V., Chouliara, E., Riganakos, K. A., \& Kontominas, M. G. (2009). Effect of $\gamma$-irradiation on the physicochemical and sensory properties of raw unpeeled almond kernels (Prunus dulcis). Innovative Food Science \& Emerging Technologies, 10(1), 87-2.

Mexis, S. F., \& Kontominas, M. G. (2009). Effect of $\gamma$-irradiation on the physicochemical and sensory properties of 
hazelnuts (Corylus avellana L.). Radiation Physics and Chemistry, 78(6), 407-3.

Pedro, A. C., Granato, D., \& Rosso, N. D. (2016). Extraction of anthocyanins and polyphenols from black rice (Oryza sativa L.) by modeling and assessing their reversibility and stability. Food Chemistry, 191, 12-0.

Re, R., Pellegrini, N., Proteggente, A., Pannala, A., Yang, M., \& Rice-Evans, C. (1999). Antioxidant activity applying an improved ABTS radical cation decolorization assay. Free Radical Biology and Medicine, 26(9), 1231-7.

Ryu, D., \& Koh, E. (2017). Influence of Cooking Methods on Free and Bound Phenolic Acids in Korean Black Rice. Journal of Food Processing and Preservation, 41(2), e12873.

Rodríguez-Pérez, C., Quirantes-Piné, R., Contreras, M. d. M., Uberos, J., FernándezGutiérrez, A., \& Segura-Carretero, A. (2015). Assessment of the stability of proanthocyanidins and other phenolic compounds in cranberry syrup after gammairradiation treatment and during storage. Food Chemistry, 174(0), 392-9.

Shao, Y., Tang, F., Xu, F., Wang, Y., \& Bao, J. (2013). Effects of $\gamma$-irradiation on phenolics content, antioxidant activity and physicochemical properties of whole grainrice. Radiation Physics and Chemistry, 85, 227-3.

Shao, Y., Xu, F., Sun, X., Bao, J., \& Beta, T. (2014). Phenolic acids, anthocyanins, and antioxidant capacity in rice (Oryza sativa L.) grains at four stages of development after flowering. Food Chemistry, 143, 90-6.

Shen, Y., Jin, L., Xiao, P., Lu, Y., \& Bao, J. (2009). Total phenolics, flavonoids, antioxidant capacity in rice grain and their relations to grain color, size and weight. Journal of Cereal Science, 49(1), 106-1.

Silva, R. C., Pino, L. M., Spoto, M. H. F., \& D'Arce, M. A. B. R. (2010). Estabilidade oxidativa e sensorial de farinhas de trigo e fubá irradiados. Food Science and Technology (Campinas), 30(2), 406-3.

Singleton, V., \& Rossi, J. A. (1965). Colorimetry of total phenolics with phosphomolybdic-phosphotungstic acid reagents. American Journal of Enology and Viticulture, 16, 144 - 58.

Sultan, N., Wani, I. A., \& Masoodi, F. A. (2018). Moisture mediated effects of $\gamma$-irradiation on physicochemical, functional, and antioxidant properties of pigmented brown rice (Oryza sativa L.) flour. Journal of Cereal Science, 79, 399-7.

Sumczynski, D., Kotásková, E., Družbíková, H., \& Mlček, J. (2016). Determination of contents and antioxidant activity of free and bound phenolics compounds and in vitro digestibility of commercial black and red rice (Oryza sativa L.) varieties. Food Chemistry, 211, 339-6.

Ti, H., Li, Q., Zhang, R., Zhang, M., Deng, Y., Wei, Z., Chi, J., Zhang, Y. (2014). Free and bound phenolic profiles and antioxidant activity of milled fractions of different indica rice varieties cultivated in southern China. Food Chemistry, 159, 166-4.

USDA (2018). Grain: World Markets and Trade. United States Department of Agriculture, Foreign Agricultural Service, Washington, DC, US, 2018, Available online: https://www.fas.usda.gov/data/grain-worldmarkets-and-trade (Accessed on May, 15th, 2018).

Zhang, H., Shao, Y., Bao, J., \& Beta, T. (2015). Phenolic compounds and antioxidant properties of breeding lines between the white and black rice. Food Chemistry, 172(Supplement C), 630-9.

Zhu, F., Cai, Y.-Z., Bao, J., \& Corke, H. (2010). Effect of $\gamma$-irradiation on phenolic compounds in rice grain. Food Chemistry, 120(1), 74-7.

\section{Acknowledgements}

The authors are deeply grateful to the Coordination for the Improvement of Higher Education Personnel (CAPES) for scholarship. 